JeDEM 11(2): 119-132, 2019

ISSN 2075-9517

http://www.jedem.org

\title{
Local Open Government: Opportunities and Challenges in Terms of Impact and Participation.
}

\author{
Renato Berrino Malaccorto* and Maricel Lonati**
}

*General Directorate of Institutional Quality and Open Government, Government of the City of Buenos Aires, Uspallata 3160, intern 7750, City of Buenos Aires, Argentina; renatoberrino90@gmail.com

**General Directorate of Institutional Quality and Open Government, Government of the City of Buenos Aires, Uspallata 3160, intern 7750, City of Buenos Aires, Argentina; mlonatigcba@gmail.com

Abstract: Through this reflection we propose to investigate and explore the possibilities offered by the implementation of open government policies in the local dimension, focusing particularly on: 1) the impact generated by open government initiatives in the improvement of processes, delivery of public services and quality of life of citizens; 2 ) the potential of these tools to advance in opening policies that involve the different branches of the State; 3 ) the possibilities offered by closeness in local governments to encourage and diversify citizen participation, and to empower the community as a driver of innovation; 4) the lessons and challenges that the implementation of these tools leave in subnational governments.

Keywords: Open Government, innovation, participation, accountability, transparency

Acknowledgement: We thank the thriving open government community, both international and local, that inspires us and helps us thinking about how to improve public policies through innovation.

\section{The value of Open Government at the local level}

\subsection{Assumptions to advance Open Government at the local level.}

In recent years there has been much talk about the possibilities offered by the implementation of open government policies in the local dimension. Many of the innovations that are happening in modern democracies begin in subnational regions and cities; processes that involve citizens in the design and control of public policies; instances of citizen feedback that take advantage of the proximity of the local dimension to close the feedback loop; opening of data and development of a civic platform oriented to specific themes which improve public services and the quality of life of citizens allowing for user experience to be taken into account; collaborative management practices 
in citizen care issues; and interoperability, coordination and openness initiatives that go beyond the Executive Branch and involve other State actors. There are many examples: Decide Madrid ${ }^{1}$; BA Obras"; Desafíos Cívicos (Civic Challenges)3; Citizen laboratories4; Openness and innovation in judicial systems 5 ; etc. These innovations motivate researchers as well as policy implementers who quickly accept the idea that local governments are the right place to collaborate, co-create and innovate. But is this really so?

Generally, we rely on the following assumptions and postulates ${ }^{6}$ when we talk about cities and local governments as privileged places to advance open government reforms:

- The local level is where citizens have a greater proximity, and where it is easier for governments to design spaces for collaboration and co-creation.

- Local governments have a broader and more direct knowledge of their territories, and of the problems that affect their inhabitants.

- Local administrations, and especially cities, tend to have more agile and less bureaucratic structures than national administrations.

- In most countries, it is the local administrations that are in charge of the provision of public services.

- The most tangible socio-economic development is occurring mainly at the local level, whether in regional areas, cities, communes, or neighbourhoods.

Based on these hypotheses, international organizations and networks such as the Open Government Partnership (OGP), the Inter-American Development Bank (IDB), the Organization for Economic Co-operation and Development (OECD), the United Cities and Local Governments (UCLG), the Economic Commission for Latin America and the Caribbean (ECLAC) and the Union of Ibero-American Capital Cities (UCCI) have created specific commissions, communities of practices, programmes, and working documents to support the proliferation of open government in local governments ${ }^{7}$. Much of their actions are framed in the $2030^{8}$ Sustainable Development Agenda,

1 See: https://decide.madrid.es

2 See: https://www.buenosaires.gob.ar/baobras

${ }^{3}$ See: http://desafios.sanpedro.gob.mx/

${ }^{4}$ See: https://www.medialab-prado.es/

5 See: https://apolitical.co/solution_article/open-justice-pioneering-buenos-aires/

${ }^{6}$ Open Government Partnership (2017), “¿Qué contienen los planes de acción subnacionales?”, ed. 2017; Open Government Partnership, UCLG (2018), “Urban 20: White Paper on Transparency and

Open Government. Building transparent, responsive and inclusive cities", Coord. María Alejandra Rico, Juana Lopez Pagán (UGLC/FEMP), Brittany Giroux Lane (OGP);

7 Some examples are: the UCCI Open Government and Transparency Working Group; the

Community of Open Government Practice of UCGL and OGP; the toolkits of the OECD Public Sector Innovation Observatory and the Open Government studies at national and local level; IDB reports and supporting documents (e.g.:https://publications.iadb.org/es/el-ecosistema-de-gobierno-abierto-en-laciudad-de-buenos-aires-un-m odelo-generador-de-cambios); the ECLAC Open Government courses.

${ }^{8}$ See: https://www.un.org/sustainabledevelopment/es/objetivos-de-desarrollo-sostenible/ 
promoted by the United Nations. Particularly, it works focusing on Goal 16, which aims to promote peaceful and inclusive societies for sustainable development, facilitate access to justice for all and create effective, responsible and inclusive institutions at all levels.

Among the networks and initiatives mentioned, the OGP Local Governments Programme stands out for having been one of the first ones to promote the development of open government action plans with co-created commitments, in subnational entities.

\subsubsection{The value of the OGP local programme for pioneer governments: results compared.}

Two years after the launch of the OGP Local Government programme, which set as objectives; the promotion of innovations and reforms of open government at the local level, where governments can participate more directly with citizens and provide many crucial public services, we access the Final reports of the Independent Review Mechanism (IRM), which evaluated the participation of the 15 local governments that formed the first subnational pioneer cohort (today 30 local governments are part of the Programme). These reports conclude that these first exercises of co-creation of action plans have been successful in generating a favourable climate for the implementation of open government reforms and the capture of political will for these issues to be included in government planning. At the same time, they point out that the commitments have made governments accountable to a greater extent; something that is of paramount importance at the local level, dimension; that citizens access services and information more directly. Moreover, the local sphere is positively valued as conducive to peer learning.

Some of the topics that we can observe in the Local Government Action Plans are: inclusion (gender, people with disabilities, youngsters, etc.); improvement of public services (transport, education, housing, etc.); Progress towards an Open State (open data portals in the Judiciary, Legislative Branches and Public Defender's offices; coordination roundtables and work); participatory budget; transparency in public purchases; anti-corruption commitments (lobby regulation, conflicts of interest, etc.).

The following indicators can be observed from the evaluation data9:

- Two thirds $(67 \%)$ of the local OGP participants had a multi-stakeholder forum. During the cocreation, $67 \%$ gave feedback on how the inputs were taken into account, and $92 \%$ were engaged in discussion during implementation.

- As already mentioned, local commitments have a much higher potential impact according to the assessment conducted by the IRM ( $80 \%$ for Local vs. $58 \%$ for National).

- Regarding challenges and results, completion at the end of the (one-year) action plan was slightly lower for Local (68\%) than completion at the end of the (two-year) action plan for National (77\%). Most local action plans did not have "stars" (well-designed and implemented commitments)

\footnotetext{
${ }^{9}$ See: OGP Explorer: http://www.opengovpartnership.org/explorer/all-data.html
} 
due to low completion rates. The local action plans had slightly more commitments with significant results $(20 \%)$. A few very strong OGP Local participants also outperformed the norm (Buenos Aires, Madrid and Ontario).

Based on these evaluations and the testimonies of the government and civilians involved, important challenges were also detected. Including: get new actors involved in participatory processes, going beyond the usual candidates; moving from data to "data in use"; promoting the use of the platforms; disseminating them and generating various instances of awareness; contemplating Civil Society Organizations as executing partners in the implementation of the commitments to obtain better results; formalising multi sectorial forums as much as possible; aligning the priorities of the Action Plan with those of the Citizenship.

\section{Participation of Buenos Aires in the OGP local programme (2016 - 2019)}

\subsection{Objectives and Expectations}

Buenos Aires is considered a pioneer city in Open Government due to its long history in terms of transparency, participation and accountability. This is reflected in the fact that the City has one of the first laws on Access to Public Information (1998) in Latin America, its update was recently passed (2016). In addition, in the last 7 years, Buenos Aires has deepened the course towards the opening of government with the sanction of open data regulations: the open data portal data.buenosaires.gob.ar (2012), publication of the Information in digital formats (2013), and implementation of the Distance Processing System (Sistema de Tramitación a Distancia - TAD) (2013).

During the administration initiated at the end of 2015, this legacy was taken and the opening policies were deepened; with a very strong focus on institutional innovation and the opening of participatory processes.

Also, at the end of 2015, the Open Government Partnership launched the first pilot programme that involves subnational governments. When applying, Buenos Aires involved the three branches of the state - executive, legislative and judicial - under the Open State paradigm, to seek sectorial commitment to its impact on citizenship and to share its experience with other provinces, cities and municipalities of Argentina.

\subsection{First Action Plan}

Since Buenos Aires was incorporated into the pilot programme of subnational entities, in midApril 2016, the City acquired a strong leadership in Open Government initiatives.

Within the Executive Branch of the Government of the City of Buenos Aires, different areas collaborate in the OGP process. The Under secretariat of Strategic Management and Institutional Quality, within the General Secretariat and International Relations, was responsible for coordinating 
the project. Furthermore, the area of access to public information and the open data sector also collaborated. And different Civil Society Organizations were convened. This space was constituted as the Governance Round Table of the process, which planned the methodology; the themes; the call and the validation of the Action Plan.

All the minutes of the process; the material; the commitments and the information about their implementation are available at the BA in OGP web platform ${ }^{10}$. Some of the specific achievements are:

- The creation of the Open Data Portal of the Ombudsman's Office ${ }^{11}$ and the Superior Court of Justice $^{12}$

- The opening of participatory practices in the Executive Branch;

- The opening of legislative information.

- The creation of the Coordination and Interoperability Table between different branches of the State and Civil Society.

- The creation of the Map of infrastructure works in schools, with their respective reporting channel ${ }^{13}$.

- The opening of transport data ${ }^{14}$ in GTFS format ${ }^{15}$, the first necessary step to work on predictive arrival systems.

- The opening of information on sexual and reproductive health services ${ }^{16}$, and a reporting and geo referencing system created by Civil Society ${ }^{17}$.

Throughout the process, twenty-seven face-to-face workshops were held, with the participation of twenty-one civil society organizations, sixteen areas of government from the three branches of state, two research institutes and a university.

Both the co-creation process and the implementation of the initiatives were evaluated by the IRM, in its final report, published in early $2018^{18}$. Among some outstanding findings that appear in it, we can observe that Buenos Aires developed and implemented the action plan pilot in a highly collaborative manner (according to the "International Association for Public Participation" scale). The central axis of the commitments with greater progress was the opening of data in the three branches of the state and in sexual and reproductive health services. For the future, it is

\footnotetext{
10 See: https://buenosaires.gob.ar/baenogp

11 See: http:// datos.defensoria.org.ar/

12 See: http://datos.tsjbaires.gov.ar/

${ }^{13}$ See: https://www.buenosaires.gob.ar/educacion/mapa-de-obras

14 See: https://data.buenosaires.gob.ar/dataset/colectivos-gtfs

15 See: https://developers.google.com/transit/gtfs/reference?hl=es-41

16 See: https://data.buenosaires.gob.ar/dataset/hospitales

17 See: https://donde.huesped.org.ar/\#/

18 See: https://www.opengovpartnership.org/countries/buenos-aires-argentina
} 
recommended to encourage reforms that promote accountability and include greater diversity of interest groups.

Regarding numbers, the Report reflects that four of the five commitments that made up the First Action Plan were fulfilled substantially or completely and that two of them constitute starred commitments, the maximum grade granted to them, taking into account the relevance to the open government values; the impact and the transformative potential and the substantial or complete implementation. In turn, it is emphasized that the five commitments implied a significant advance in the opening of government practices. The system of public monitoring and control of the plan was also highlighted, it consisted in face-to-face meetings, virtual monitoring boards and a public document repository ${ }^{19}$.

Regarding observations and challenges, it is highlighted that the most successful commitments are the ones which have Civil Society Organizations as partners in the implementation of the commitments; a call to go the extra mile; going from data to data in use; taking into account the dissemination of the opening practices and the promotion of reuse (thus avoiding a lukewarm participation);moreover, we are encouraged to put more focus on accountability; taking greater consideration of the time and resources of Civil Society Organizations.

In terms of recommendations, the following stand out: the invitation to expand and extend citizen participation beyond the "usual suspects"; to formalize the multi sectional forum as much as possible; incorporate new areas of government; strengthen the accountability dimension; designate clear responsibility for each milestone to be able to respect the expected time and align the priorities of the plan with the citizenship agenda.

\subsection{Second Action Plan}

In 2018, the Local Government Programme of the Open Government Partnership was consolidated; expanding the number of participating cities and the City co-created its Second Action Plan. Its implementation will take two years (from September 2018 to September 2020), it includes five global commitments that work as axes which comprise of various milestones.

For the Second Action Plan, we seek to:

- Take advantage of the local dimension to solve problems that have an impact on improving the quality of life of neighbours.

- Empower the community as a driver of innovation.

- Use the logic of the collaborative economy: the best ideas may be dispersed in the community.

- Rethink processes with a focus on user experience.

- Apply technology to find creative solutions.

19 See: https://www.buenosaires.gob.ar/agendadetransparencia/gobierno-abierto/buenos-aires-enalianza-par a-el-gobierno-abierto/seguimiento 
For this new process, we sought a qualitative leap by extending the concept of Open Government through the participation of a greater diversity of actors and incorporating in the commitments different pillars of Open Government; going one step beyond the opening of information. In addition to civil society organizations; it was proposed to work with the private sector, academia and the unorganized citizenship. Likewise, efforts were made to open the possibility of sending proposals to all neighbours, in order to analyse the most relevant public interest issues.

The local dimension facilitates the gathering of collective creativity, dispersed in the different actors of the city, for the co-creation of answers. To achieve the expansion of the process, different strategies were implemented that incorporated more instances of participation in the methodological design.

The co-creation process of the Second Plan was conceived from the coexistence of three instances of participation with different dynamics and specific methodologies. We worked on participatory methodologies guided by "broad" thematic axes (that is, axes that could involve different subthemes and components), in order to achieve various milestones that could create a commitment and cover more than one pillar of Open Government, without setting aside proposals that are considered viable and be open to new ideas that may arise in the face-to-face stage, and take advantage of the two years of implementation to generate more ambitious commitments.

Number of participants in the co-creation on-site stages:

Total of participants: 261

Total of participants in workshops: 176

Total of participants in deliberative forums: 85 (In terms of gender, 44 men and 41 women participated in the forums.)

Total of Government participants (per area): 29

Total of participants from Civil Society Organisations (per organisation): 20

Total of Academy participants (por network/or institution): 5

Total of participants from the Private Sector: 2

The commitments drafts were submitted to public consultation during September. It was done through the web portal "BA Elige" 20 , which uses Consul technology and it was disseminated by the Governance Round Table through different channels: mailing, social networks, word of mouth, etc.

\section{The commitments}

Opening and Innovation for an Open State. Some outstanding milestones are: Open data and reuse; Evaluation and monitoring rates; Open data portal of the Legislature and Opening of the Office of Citizen Services; Judicial Innovation Laboratory; Opening of information on citizen participation processes.

\footnotetext{
${ }^{20}$ https:// baelige.buenosaires.gob.ar/debates
} 
Human Scale City. Some highlighted milestones include: Urban Dynamic Map; Platform for innovation of sidewalks; Portal for older adults.

Mobility and Transport: user experience. Some outstanding milestones are: Opening of information on sustainable mobility; Opening of information and education and coexistence campaigns related to the Underground.

Open government for gender equality. Some highlighted milestones are: Opening of information and collaborative evaluation of the Comprehensive Sexual Education program; Open budget on gender topics.

Housing: indicators system. Opening of information on housing through a web platform with open and georeferenced data and periodic updates.

The implementation term of the 2nd Action Plan will be from September 2018 to September 2020.

The complete document with the follow-up methodology agreed by the Governance Board can be consulted in the process' public repository ${ }^{21}$.

\subsection{The impact in the City of Buenos Aires}

The results of the commitments of the Action Plans find: specific initiatives aimed at, through the principles of Open Government; generating spaces of trust between citizens and the State, moving towards a paradigm of Open State, and improving public services. As detailed above, the commitments of the First Plan were implemented and evaluated, and those of the Second Plan are currently in the implementation phase.

Likewise, when we applied to be part of the group of pioneer cities of the Open Government Partnership, one of the results we were seeking was to continue improving through the exchange with other cities, and the link with international initiatives and organizations which promote Good practices in open government. Multi sectional and multilevel collaboration, constituting communities of practice, allows us to share information; build knowledge; develop initiatives and solve specific problems and challenges. Examples of some interesting exchanges that were performed are: collaborative work with the Open Contracting Partnership to publish the City's purchases and hiring under its standards; workshops for exchanging experiences in citizen care systems from cities of the OGP Local Governments Programme; open source software exchanges (Consul between Madrid and Buenos Aires; Open Public Works between Buenos Aires and San Pedro in Mexico); etc.

It is worth mentioning that the City's commitment to the values of the Open Government Partnership goes beyond the Action Plan, and that this is reflected in the initiatives that make up the City's Open Government Ecosystem, that have been launched or renewed previously. The OGP

${ }^{21}$ See:

https://www.buenosaires.gob.ar/agendadetransparencia/gobierno-abierto/buenos-aires-en-alianza-par a-el-gobierno-abierto/seguimiento 
framework has supported the local Open Government Community to promote, redesign and enhance initiatives in this area. In turn, the synergies generated from the Action Plan have brought positive externalities that go far beyond the commitments that were initially set in the Plan document.

The Open Government Ecosystem of the City of Buenos Aires ${ }^{22}$ brings together the policies and actions carried out by the City in terms of governmental openness. We work to, (through open government tools) improve internal and external processes and generate more efficient public services. We seek to achieve an increasingly modern and agile public administration and work collaboratively with citizens to solve public interest problems.

The Open Government Ecosystem model was documented by the IDB ${ }^{23}$, focusing on how it is a model that generates changes in the structure of public administration. The document analyses the open government management model of CABA within the government and its organizational culture, as well as its external side, that is; the provision of services and it's relationship with citizens. The management model developed in the city is the result of collaborative work between the different government ministries. Likewise, the model incorporated the participation of citizens and Civil Society Organizations, which has increased confidence in government and accountability. Based on these specific achievements; the City's Open Government Ecosystem still has the challenge of improving practices to close the feedback loop in the relationship between users of the ecosystem and the public administration.

\section{Considerations on OGP and other frameworks to advance Open Government reforms.}

\subsection{OGP as a framework for change. Reflections on the programme for local governments.}

From the experience of the City of Buenos Aires in the Open Government Partnership and the analysis of the cases of the other subnational pioneers; we can say that the Local Government Programme is an effective platform for the promotion of institutional innovation through participation, collaboration, and the use of technology for government innovation. It generates opportunities for the creation of innovative products which offer specific answers to the needs of civil society or which contribute to the generation of public value; while laying the groundwork for strengthening communities of practice among government employees, Civil Society Organizations, and citizens.

On the one hand, the structure of the commitments proposed by the OGP, the limited time frame and the limit on the level of commitments, help to structure the City's participation in the Programme to obtain measurable and comparable results, and to work on implementable and

\footnotetext{
22 See: https://gobiernoabierto.buenosaires.gob.ar

${ }^{23}$ See: https:// publications.iadb.org/es/el-ecosistema-de-gobierno-abierto-en-la-ciudad-de-buenos-airesun-m odelo-generador-de-cambios
} 
concrete initiatives. But on the other hand, this framework often works as a limitation, leaving initiatives and voices outside the action plans. The challenge is to find the most effective way to channel these impulses. We believe that the Action Plans should be a road map, and delimit as far as possible the grounds of the reforms in which progress is sought. We should consider them as a living document, which is iterating, and that can take feedback to achieve a greater impact on the Open Government Agenda.

Certainly, each paradigm change sets out considerable challenges for complex organizations. Of course, every paradigm shift presents considerable challenges in complex organizations. Change agents are often dispersed and it is likely to face issues related to resistance, unawareness and lack of prioritisation, even when there is support from the leadership positions. In Buenos Aires, we have faced many of those difficulties, typical of these kinds of changing processes.

Furthermore, change agents need to have a story to tell. They need a framework to enhance their efforts and gather them cohesively. That is, symbolic resources. Certainly, Buenos Aires already had a story to tell about open government, but its incorporation into OGP managed to bring together many of these initiatives. It was thanks to the spirit of the OGP that we managed to put together the open data efforts with the citizen participation initiatives that were being developed within the city government. OGP was the perfect excuse to incorporate and link the government offices that previously did not participate in the principles of open government and we managed to identify new solutions for their problems, from a new perspective. The question that guides us is: if you are a public official, how do you create new ways of working within the entrenched bureaucracies?

Moreover, when we analysed the work we were carrying out from the open government perspective, we realised that many government institutions were already working on open government without knowing it. They were working without a framework. Nevertheless, frameworks are useful because they represent a source of inspiration and help enhance reform efforts and establish links between institutions without which change cannot be achieved (or if it happens, the process is very slow and of low impact). In addition, frameworks are important to drive changes: when institutions are undecided; frameworks encourage them to take reform actions and help build a relationship of trust between the institutions. There are many incidences where framework can be seen to have a beneficial outcome..

In our opinion, Buenos Aires is an excellent example to demonstrate that the OGP can serve as a framework for change. We are sure that other cities have similar stories. This reflection is a very promising tool for further research; sharing experiences and reflecting on experiences. Creating change is difficult, but it is easier when you are not alone.

\subsection{Complementary paths for progress in Open Government reforms at the local level.}

The dynamism of the globalized world and of current democracies urges us to constantly rethink strategies to advance open government agendas; trying to adapt them to the different realities, including marginalised or vulnerable sectors of the population whilst contemplating the technological innovations that happen constantly. 
It is in this context that we can think of different ways to deepen these agendas at the local level; complementing the OGP plans (taking into account that it is impossible for the Programme to cover all existing local governments).

One device that can help us in this regard is the construction of Communities of Practice (CoPS). A "Community of Practice" is one that is made up of a group of peers with the common purpose of working together to share information, build knowledge, develop initiatives and solve specific problems and challenges ${ }^{24}$. The Communities of Practice are characterized by the willingness of their members to participate and generate a continuous interaction in the development of the area of such practice. They constitute an effective way to face unusual problems by sharing knowledge beyond the edges of traditional structures. Therefore, institutions interact from a different paradigm that enables the integration of informal models with bureaucratic models, where the Communities of Practice can provide a dynamic way of interaction which is more permeable to the context, thus ensuring fast and dynamic responses to the latter. These new models provide various opportunities for the strengthening of open government plans and policies at the local level, strengthening the pillars of transparency, innovation, accountability and participation through collaboration.

Other possibilities are connected to; as previously stated, understanding OGP as a "framework for change", and generating positive models and externalities that go beyond the Action Plans (as was the case with the Open Government Ecosystem of the City of Buenos Aires). In this context, it is important to highlight the findings of the IDB case study on the Buenos Aires Open Government Ecosystem; previously mentioned, which sheds light on the importance of planning and management systems as a catalytic factor for the successful implementation of open government initiatives and the advantages of the institutional design (or "Government Centre") as a facilitator of cross-cutting policies.

There are other possibilities or models in which national governments have guaranteed and promoted these agendas towards the local governments that it's composed of. Some examples are being studied to evaluate the best strategy that OGP can carry out to work locally. We found the case of the Third Action Plan of Argentina, which included a broad subnational commitment, with various milestones that involved several local governments in the country. Indonesia followed the same strategy. Another interesting example can be seen in Mexico: since 2015, the INAI (National Institute for Transparency, Access to Information and Protection of Personal Data), an autonomous body in Mexico, has worked to develop open government actions at a local level in Mexico. By working with local governments that express their interest and with the support of civil society actors, the initiative encourages the creation of permanent technical and governmental dialogue mechanisms with the civil society, carrying out the development of local commitments. In 2017, 26 out of the 32 states of Mexico participated in Open Government processes.

${ }^{24}$ See: https:// florille.files.wordpress.com/2010/02/kaufman2005.pdf. “Comunidades de práctica y back office incremental. El gobierno electrónico hacia la sociedad de la información: la experiencia del Foro Informático argentino". Ester Kaufman, X International Congress of CLAD on State Reform and Public Administration, Santiago, Chile, 18 - 21 Oct. 2005. 
These are just a few ideas among the many that can be found. We believe that strategies require constant reflection, and each context invites us to think about the appropriate lines of work to deepen these agendas.

\section{Concluding thoughts: lessons and challenges.}

An open government is a government which broadens and eases access to information to all citizens in order to promote accountability and diverse stages for co-creation of public policies. It represents a change of paradigm, implying a new way of relating citizens to their representatives. It is a transparent government, accountable for its actions, which involves citizens in the decision-making process.

We firmly believe that the inclusion of local governments has a tremendous potential for positive change thanks to the mechanisms of direct democracy and citizen-centred governance implemented by such subnational entities. The partnership between the government and the civil society is the main engine of the project. When we listen, residents commit themselves. Opening and disseminating information about the ongoing processes allows us to build trust among citizens. The creation of channels of dialogue and co-creation allows us to develop more legitimate policies that can better respond to the needs of citizens.

The postulates and cases presented lead us to think about various lessons and challenges that we will have to take into account in order to continue working on these agendas successfully in the future. We mention some of them below, conceiving the debate as something "alive"; in constant evolution and with the idea that this work serves as a basis to successfully scale up the initiatives.

We consider that a comprehensive strategy is necessary to deepen the tools of open government both within and outside the sphere of Public Administration. This implies an approach through three edges: a strong political will to work this agenda; a robust regulatory framework which provides us with legal certainty and policy stability and an interdisciplinary, flexible work team that proclaims creativity and understands the notion and the need to create community.

We understand that multispectral and multilevel collaboration is key in the sense of creating community. It is an agenda that is often difficult to push forward, but it is much easier if we do it with allies from different sectors who share the importance of these values.

Another key point is to never forget who the final recipient of all these efforts is: the citizen. In this sense, it is of paramount importance to align the open government agenda with the society's priority agenda. Cities allow us to generate closeness to citizens, and this is an ideal opportunity to apply open government tools on key and specific issues: improve public services; include the voices of vulnerable populations and advance this agenda in the different branches of the State. At the same time, it allows us to listen and take into account the user experience. This is a key factor to ensure that the efforts made have a real impact and that we can see and measure the usability of the generated devices. We believe that the local dimension is the ideal scenario to close the feedback 
loop: the government opens information and participatory instances; society gives its feedback (a suggestion, a product, etc.); and the government uses these inputs to improve its public policies.

It is also very important to measure and evaluate the impact of Open Government initiatives. Many times a lot of effort is put into the implementation of the Agenda, but we lose sight of the impact it generated. Constant evaluation prevents the initiatives from falling into disuse or losing virtuality, as well as this it allows for constant adaptation and improvement. In this sense, as stated above, planning and management systems as a catalytic factor are of paramount importance for the successful implementation of open government initiatives, as well as the advantages of institutional design (or "Government Centre") are as a facilitator of transversal policies. This also allows us to measure and perceive the part of open government that is not seen: improvement in internal processes, advances in interoperability and greater efficiency in resource management.

We believe it is also important to bring the notion of "Open Washing" to the debate. This concept refers to the recent opening (of information, processes) in a certain area (not sensitive, or not uncomfortable), in order to maintain or lower the opening bar in another more sensitive area, which would have a greater potential impact. In short, this term alerts us to the danger of transmitting the idea of openness while the most important decisions and actions remain closed and opaque. It is the job of the Open Government Community as a whole to notice these cases and work to reverse them.

Another lesson learned is related to the need for an awareness dimension that accompanies these processes. Even though the concept of Open Government is not new, it is not entirely known. For that reason, we understand that in addition to the work roundtables and meetings proposed by the OGP process, we shall include new methodologies which involve a variety of actors, and pedagogical actions to raise awareness about open government in general, and OGP in particular. This in turn, will leave installed capacity in the public administration, and generate a vibrant and collaborative society, thus avoiding falling into personality cults, and facilitating the sustainability of these agendas.

An open government includes tools that help us to be closer to citizens and to become better public servants. To produce specific solutions to specific issues. It is a collaborative (permanent) task of the whole Community to work towards democracies that are increasingly committed to these pillars.

\section{References}

ECLAC. (2018). Panorama de la Gestión Pública en América Latina y el Caribe: Un Gobierno Abierto centrado en el ciudadano. Retrieved from: https://www.cepal.org/es/publicaciones/42396-panorama-lagestion-publica-america-l atina-caribe-un-gobierno-abierto-centrado

Cruz-Rubio, C. N. (2014). Hacia el gobierno abierto: Una caja de herramientas. Washington, DC: Organización de los Estados Americanos (OEA). Retrieved from: https://drive.google.com/file/d/0Bx3FnhDewC6rTlYwNzhYcU9rd2xNbzB4TTdGbW5Pc nV0aWRn/view 
Herrero, A. y Castaglona, A. (2019). El ecosistema de Gobierno Abierto en la Ciudad de Buenos Aires: Un modelo generador de cambios. Retrieved from: https://publications.iadb.org/es/el-ecosistema-degobierno-abierto-en-la-ciudad-de-bu enos-aires-un-modelo-generador-de-cambios

Hilaire Chaneton, P. y Casas, P. (2019). In Buenos Aires, a pioneering open justice programme is rebuilding trust. Apolitical. Retrieved from: https://apolitical.co/solution_article/open-justice-pioneering-buenosaires/

Kaufman, E. (2005). Comunidades de práctica y back office incremental: el gobierno electrónico hacia la sociedad de la información. La experiencia del Foro Informático argentino. Retrieved from: https://cladista.clad.org/handle/123456789/3636

OGP. (2017). ¿Qué contienen los planes de acción subnacionales? Retrieved from: https://www.opengovpartnership.org/sites/default/files/OGP_SNAP-Report_2017_ES.p df

OGP y UCLG. (2018). Urban 20: White Paper on Transparency and Open Government. Building transparent, responsive and inclusive cities. Retrieved from: http://www.urban20.org/item/ejes-y-documentosclave/U20_WP_Transparency_in_citi es.pdf

Ramírez-Alujas, Á. y Dassen, N. (2016). Vientos de cambio II: Avances y desafíos de las políticas de gobierno abierto en América Latina y el Caribe. Washington: Banco.

Interamericano de Desarrollo.

Retrieved from: https://drive.google.com/file/d/0B4tflRO7jAQsRnFvR09kNk5hSGs/view

\section{About the Authors}

Maricel Lonati

Maricel Lonati is Operational Manager of the General Directorate of Institutional Quality and Open Government. She has a degree in Political Science and International Relations, and has a Master's Degree in Public Policy and Development Management from Georgetown University - UNSAM. Previously, she was responsible for the area of strengthening citizenship in the Consciousness Association.

\section{Renato Berrino Malaccorto}

Renato Berrino Malaccorto is a Lawyer, with orientation in International Law, graduated with honors from the Law School, University of Buenos Aires, where he teaches Constitutional Law and Criminology. He works as a Project Manager in the General Directorate of Institutional Quality and Open Government of the Government of the Autonomous City of Buenos Aires. His responsibility is to design, manage and evaluate projects within the Open Government axis. He works on issues of citizen participation, institutional innovation, transparency, access to information, accountability. He also conducts research on comparative policies and coordinates the process of the City of Buenos Aires in the Open Government Partnership. 